\title{
Sobre a possibilidade de construção de uma Filosofia Concreta em Herbert Marcuse
}

\section{J orge Coelho Soares*}

Universidade do Estado do Rio de Janeiro - UERJ, Rio de Janeiro, RJ, Brasil

Resumindo o sentido dessas questões, não se deve, para começar, reconsiderar a filosofia a partir da existência humana concreta e questionála a partir dessa existência?

Herbert Marcuse

Entre os pensadores da Escola de Frankfurt, Herbert Marcuse (18981979) é, certamente, o mais otimista. Mais resolutamente hegeliano e ligado ao potencial utópico das reflexões de Marx do que Adorno e Horkheimer. Durante sua trajetória intelectual, nunca perdeu a esperança na possibilidade de construção de um mundo reconciliado pela superação de suas contradições. Seu pessimismo aparente não era senão a expressão de um otimismo sem ilusões.

Os trabalhos do "jovem Marcuse" representam a primeira tentativa original de construir e desenvolver um marxismo fenomenológico, sob influência de Heidegger. De 1928 a 1932 Marcuse, sob a orientação de Heidegger, elaborou uma tese sobre a Ontologia de Hegel e a Teoria da Historicidade. Porém, desde 1925, Marcuse começou também uma aproximação intelectual, sistemática, com a obra de Marx (1818-1883). Sua obra, daí em diante, esteve sempre marcada pela sua presença, quer fazendo dele o seu interlocutor privilegiado, quer dialogando criticamente com os pensadores, classicamente considerados como os grandes "interlocutores" de Marx, como é o caso de Hegel (1770-1831). Marcuse foi também o primeiro filósofo, em 1932, a publicar uma resenha crítica e interpretativa ${ }^{1}$ dos Manuscritos Econômicos e Filosóficos de Marx, que acabavam de ser publicados por Landshut e Mayer. Este livro, escrito por Marx em Paris nos primeiros meses de 1843, é composto de uma série de escritos onde ele esboçava uma concepção humanista do comunismo, "influenciada pela filosofia de Feuerbach e baseada num contraste entre a natureza alienada do trabalho no capitalismo e uma sociedade comunista, na qual os seres humanos desenvolveriam livremente sua natureza em produção cooperativa" (MCLELLAN, 1988, p. 239.) Estes manuscritos, mais tarde conhecidos como Manuscritos Econômicos Filosóficos, permaneceram inéditos até 1930. 
Marcuse, tanto quanto Marx, acreditava na força revolucionária da Filosofia e via na mesma um manancial fértil e inesgotável de reflexão para dar conta do homem no mundo, a partir do qual sempre acreditou poder elaborar uma Filosofia Concreta como instrumento de luta e libertação.

Objetivando concretizar a tarefa de construir esta Filosofia Concreta, publicou entre 1928 e 1932 uma série de artigos na Revista Gesellschaft, bem como na Archiv für Sozialwissenchaften und Sozialpolitik. Destes artigos, quatro se destacam: Beiträge zu einer Phänomenologie das Historischen Materialismus (1928), Über Konkrete Philosophie (1929) e Zum Problem der Dialektik (Parte I em 1930, Parte II em 1931) e Transzendentaler Marxismus (1930) ${ }^{2}$.

Destes textos, o Über Konkrete Philosophie é o que melhor demonstra esta tentativa de Marcuse de amalgamar tendências que, naquela época - no "calor" da recentíssima publicação de Ser e Tempo e no contexto da crise da República de Weimar - poderiam esconder as contradições, que hoje são tão "fáceis" de apontar.

Por outro lado, o impacto intelectual de Heidegger sobre Marcuse tinha sido considerável, o que nunca foi negado por ele. Marcuse, durante algum tempo, acreditou também que as idéias de Heidegger e Marx poderiam confluir na mesma direção, fertilizando-se mutuamente e preenchendo as lacunas que ambas possuíam.

No marxismo, que se apresenta como uma "ciência estrutural" onde todos os fatos históricos estão relacionados a estruturas mas não à existência humana, há sempre o perigo de se descartar o ser humano real e concreto das análises e se cair, por exemplo, num economicismo esterilizante e burocrático. Heidegger, por sua vez, trabalha com abstrações da realidade, fala em historicidade mas nunca em história real. Marcuse acreditou que aí havia uma lacuna a ser preenchida pelo materialismo histórico para o qual "ensinaria" a Heidegger que a história se cristaliza nas relações sociais concretas, nas relações de produção e poder. Em 1929, Marcuse tenta demonstrar que esta dupla fecundação era viável.

Inicia o texto Über Konkrete Philosophie com uma nota, que serve ao mesmo tempo de esclarecimento de suas intenções, de tributo ao mestre - que ele via como seu maître à penser naquele momento - e explícita declaração do que mais tarde ser visto por ele como um equívoco:

O presente estudo tenta resgatar, a partir da posição que o livro de Heidegger Sein und Zeit elaborou para a filosofia fenomenológica, a possibilidade de uma filosofia concreta e sua necessidade na situação atual (MARCUSE, 1969, p. 121).

Marcuse deixou claro que o seu objetivo, ao escrever este texto, era não somente o de aceitar como sua a problemática heideggeriana de 
Ser e Tempo, mas retirar daí os elementos filosóficos que poderiam compor o que ele imaginava que fosse uma Filosofia Concreta. Esta interpretação de Marcuse em relação a obra máxima de Heidegger, é hoje apontada unanimemente como um equívoco. Em Heidegger, esta exigência de um "concreto" é totalmente estranha e deslocada.

A perspectiva de Marcuse se apresenta, então, fundamentalmente em contradição com a reflexão ontológica de Heidegger e

(...) quando Marcuse emprega a palavra Dasein, pode-se duvidar que ele dê a este termo o mesmo sentido a ele atribuído pelo autor de Sein und Zeit (PALMIER, 1973, p. 20).

Nada é mais estranho à abordagem heideggeriana, do que tomar uma fábrica como objeto possível de análise fenomenológica. E é exatamente isto que Marcuse fez: "Tomemos um exemplo. Eu olho a fábrica que está diante de mim" (MARCUSE, 1969, p. 130 e sgts). E nas páginas seguintes ele tentou, seguindo 0 método fenomenológico, chegar à essência do que é, em si, a fábrica - ao mesmo tempo que ressaltava a "historicidade do objeto fábrica e de sua ligação semântica com a existência humana" (p. 141).

Marcuse definiu também neste texto o que ele considerava o objetivo da atividade filosófica: a Filosofia Concreta almejada por ele, teria por missão precípua superar a inautenticidade da existência, permitindo a supressão de suas causas históricas materiais. Desta forma, a filosofia poderia, finalmente, realizar o que ele considerava a mais nobre missão: "unir a teoria e a prática" (MARCUSE, 1969, p. 131).

O texto Sur la Philosophie Concrète, submetido por Marcuse mais tarde, a um olhar mais apurado e crítico, se revelou à ele mesmo como uma tentativa frustrada e mesmo equivocada de estruturar as bases de uma Filosofia Concreta. A angústia de uma existência humana concreta historicamente determinada, foi a razão de todos os seus escritos posteriores e já que desde 1929, Marcuse estava persuadido de que a filosofia não poderia separar o mundo da sua inserção numa significação histórica, que Ihe daria sentido. Desta forma, o seu projeto de descrição fenomenológica da existência alienada pelo capitalismo - meramente esboçada no fim dos anos 20 e início dos anos 30 - só tomou sua feição acabada nos anos 50.

Por outro lado, Marcuse posteriormente percebeu também que, para estabelecer os fundamentos do seu pensamento negativo, da sua teoria crítica da existência, concreta e historicamente determinada, era necessário estabelecer novas parcerias teóricas. E ele as fez, através de Marx, de Hegel e, mais tarde, com Freud.

Poderíamos por fim, resumir os objetivos de todos os seus escritos entre 1928 e 1932, onde o texto Sur la Philosophie Concrète é o mais representativo desta sua fase apontando algumas de suas 
características: Marcuse definiu o caráter profundamente prático e político de sua concepção de filosofia, cuja meta é a análise e transformação da existência concreta dos indivíduos; ele tentou reunir e amalgamar influências contraditórias, que haviam marcado profundamente suas reflexões iniciais, como as advindas de Heidegger, Husserl, Lukács, Kierkegaard, Hegel e Marx; ele procurou também deixar claro sua independência em relação a todas as principais correntes filosóficas do seu tempo. Apesar do esforço de alguns teóricos posteriormente, não é possível, efetivamente, enquadrá-lo como "discípulo" de Husserl, menos ainda de Heidegger, ou ainda como um marxista ortodoxo, ou mesmo como um clássico hegeliano.

De qualquer forma, estes escritos já deixavam claro que Marcuse já havia formulado para si mesmo as questões essenciais que norteariam toda a sua reflexão subsequente. Neles, Marcuse já se perguntava sobre os fundamentos de uma existência concretamente autêntica e como seria possível vivê-la nas condições objetivas de uma história em movimento. Toda a sua obra futura, em essência, foi a tentativa de responder a estas questões.

Quanto a Heidegger, Marcuse viu sempre nele um grande filósofo, que construiu uma obra de imenso significado, mas que ignorou os problemas concretos e essenciais do mundo contemporâneo. Somente muito mais tarde, já nos anos 50 e 60, é que Marcuse conseguiu explicitar a sua "superação" do pensamento original heideggeriano e criticar a Heidegger, como um filósofo que optou viver "fora do mundo". É à Heidegger que ele endereça uma nota de rodapé colocada na sua obra de 1964:

\begin{abstract}
Para evitar mal-entendido: não creio que a Frage nach dem Sein e perguntas similares sejam ou devam ser uma preocupação existencial. O que foi significativo nas origens do pensamento filosófico, bem se poderá ter tornado destituído de significado no seu fim, e a perda de significado pode não ser decorrente da incapacidade de pensar. A história da humanidade deu respostas definidas à "questão do ser" e o fez em termos bastante concretos, que provaram sua eficácia. O universo tecnológico é uma delas (MARCUSE, 1967, p. 136) .
\end{abstract}

Marcuse conservou, porém, para sempre, o que Abbagnano chamou de "impulso heideggeriano". Foi um fiel herdeiro de suas inquietações filosóficas. Sempre houve entre eles uma diferença essencial: para Marcuse, o que sempre lhe interessou foi o homem como ser no mundo, ancorado e prisioneiro de uma história em movimento, o homem como uma realidade concreta e social. Para Heidegger, o homem foi sempre "um locus ou uma voz do Ser" (ABBAGNANO, 1982, p. 2105). 


\section{Referências Bibliográficas}

ABBAGNANO, N. Dicionário de Filosofia. São Paulo: Mestre Jou, 1982.

HEIDEGGER, M. Ser e Tempo. Petrópolis: Vozes, 1988/1993. 2 v.

MCLELLAN, D.; MARX, K. H. In: BOTTOMORE, T. Dicionário do Pensamento Marxista. Rio de Janeiro: Jorge Zahar, 1988, p. 238240.

MARCUSE, H. Philosophie et Révolution. Paris: Denël/Gonthier, 1969.

Zàhar, 1967.

I deologia da Sociedade Industrial. Rio de Janeiro:

PALMIER, J. M. Marcuse et la Nouvelle Gauche. Paris: Pierre Belfond, 1973.

RAULET, G.; MARCUSE, H. In: Philosophie de L'Émancipation. Paris: PUF, 1992.

UNIVERSELLE. Les Cuvres Philosophiques. v. 1. Paris: PUF, 1992. 2V., p. 1878-1888.

VANDENBERGHE, F. Une histoire critique de la sociologie allemande. Aliénation et réification. Tome II. Paris: La Découverte, 1998.

\section{Endereço para correspondência}

Jorge Coelho Soares

Universidade do Estado do Rio de Janeiro, UERJ, Rua São Francisco Xavier, 524, Bloco F, 10 andar, sala 10.019, CEP 20550-900, Maracanã, Rio de Janeiro - RJ, Brasil

Endereço eletrônico: jorge.coelho.soares@gmail.com

\section{Notas}

*Psicólogo; Doutor em Comunicação e Cultura - UFRJ; Professor Adjunto e pesquisador do Instituto de Psicologia e do Programa de Pós-Graduação em Psicologia Social da Universidade do Estado do Rio de Janeiro - UERJ, Rio de Janeiro, RJ, Brasil

${ }^{1}$ Marcuse, Neue Quellen zur Grundlegung des Historischen Materialismus, publicado originalmente na revista Die Gesellschaft, Vol. IX, 1932. Este texto foi traduzido para o português por Vamireh Chacon em 1968 - Editora Tempo Brasileiro - com o título de Novas Fontes para a Fundamentação do Materialismo Histórico.

${ }^{2} \mathrm{O}$ primeiro artigo citado, foi publicado pela Revista Philosophische Hefte; o segundo na Archiv für Sozialwissenchaften und Sozialpolitik; o terceiro e o quarto na Revista Die Gesellschaft. 